\title{
A netnographic study of P2P collaborative consumption platforms' user interface and design ${ }^{\text {is }}$
}

\author{
Javier de Rivera ${ }^{\mathrm{a}}$, Ángel Gordo ${ }^{\mathrm{a}, *}$, Paul Cassidy ${ }^{\mathrm{a}}$, Amaya Apesteguía $^{\mathrm{b}}$ \\ a Sociology IV, Facultad de CC Políticas y Sociología, Campus de Somosaguas, s/n. Universidad Complutense de Madrid, Pozuelo de \\ Alarcón, 28223 Madrid, Spain \\ b Organización de Consumidores y Usuarios, OCU Ediciones, Calle de Albarracín, 21, Polígono Julián Camarillo, Spain
}

\section{A R T I C L E I N F O}

\section{Article history:}

Received 3 February 2016

Received in revised form 18 May 2016

Accepted 11 September 2016

Available online $\mathrm{xxx}$

\section{Keywords:}

Netnographic protocol

Sharing economy

User interface design

Peer economy

Social impact

\begin{abstract}
A B S T R A C T
Although still embryonic, collaborative consumption and the sharing economy have become social and economic phenomena in just a few short years, yet there is little consensus on how to define them. The current classificatory schema or typologies of platforms have some weaknesses. Sectoral classifications, technological functionality, and discursive modes of understanding sharing and collaborative economies all provide valuable insights, but when taken individually important gaps are evident, not least in their inter-system isolation, but most particularly when technology, such as platform architecture and user interfaces, is disassociated from wider social and economic conditions of possibility. In order to build on previous research we set out to develop a more complex understanding of collaborative consumption by studying platform architecture, interface, design and informational content to examine how technological affordances of digital platforms' structure social interaction. In order to carry out the research we designed a netnographic protocol that systematised data collection across four dimensions of platforms' technological structure and informational content: functionality and usability; trust and virtual reputation; codes of conduct and community footprint. Data was collected on fifty-five platforms, including forty-seven across Belgium, Italy, Portugal and Spain, as well as eight international platforms. Following factor and cluster analysis, and on the basis of the theoretical understandings of the sharing and collaborative economy, we developed a typology that grouped platforms into three groups: network, transaction and community oriented.
\end{abstract}

(C) 2016 Elsevier B.V. All rights reserved.

\section{Introduction}

Although still embryonic, collaborative consumption and the sharing economy have become social and economic phenomena in just a few short years. Yet there is little consensus on what they are; collaborative economy, sharing economy, gig economy, on-demand economy, peer economy, are just some of the terminology that have been commonly used to describe this area of economic and social practice. Despite the apparent novelty of these terms, collaborative, sharing and communal

\footnotetext{
is The research that is described has been funded by a number of European consumers associations:, Organización de Consumidores y Usuarios (OCU) Spain; Test Achats-Test Aankoop, Belgium; Altroconsumo, Italy and Deco Proteste, Portugal, in collaboration with Cibersomosaguas Research Group (Universidad Complutense de Madrid) and Ouishare Spain as advisor.

* Corresponding author.

E-mail address: ajgordol@cps.ucm.es (Á. Gordo).
} 
practices already existed and are well rooted in societies across the world, and are documented in a rich stream of research (Lamberton, 2016). It is also clear that industrialization and

the shift to individualist consumer oriented societies in the 19th and 20th century did much to undermine and reduce such communal practices (McLaren and Child, 2013). However, and somewhat ironically, such social and economic changes also foregrounded the popular return to 'sharing' that we have witnessed in the last number of years. Excessive consumption throughout the later half of the 20th century, for example, would create a massive stockpile of under-used assets -recently valued at \$5 trillion (PWC, 2015)- the 'unlocking' of which is one of the cornerstones of the sharing and collaborative economy proposition. The backdrop of economic recession and impending environmental catastrophe would also make the disaffected millennial generation eager recipients of the sharing and collaborative economy propositions.

Collaborative and sharing economy platforms offer a cultural antidote to individualism, through shared community values, and greater consumer empowerment, not only as purchasers in terms of choice and convenience, but most uniquely as prosumers, ${ }^{1}$; or micro-entrepreneurs (Torregosa, 2013). Through horizontal and participatory structures the sharing and collaborative model has proffered a paradigm shift that could "solve many of the complex challenges the world faces" (Ouishare, para. 2). And of course, the collaborative economy is driven and enabled by digital technology and infrastructure that makes possible the economies of scale necessary for distributed networks. Furthermore, the technological functionalities of platforms (websites and apps) enable, facilitate and mediate exchanges and sharing between peers to create alternate and stable marketplaces that subvert traditional producer to consumer models.

Mostly driven by economic, cultural and technological factors (Barnes and

Mattsson, 2016) the success and popularity of these multi-sided marketplaces (Hagiu and Wright, 2015) is evident in a current market valuation and exponential growth predictions ${ }^{2}$ Currently estimated at $\$ 15 \mathrm{bn}$ and forecast to grow twenty-fold by 2025 (PWC, 2015). (PWC,

2015), as well as current and predicted consumer participation rates (Nielsen, 2014; OCU, 2016). However, it is important to note

that the sharing and collaborative economy extends beyond reuse and redistribution of consumer goods and services to finance, education, transport and almost all areas of social and economic activity. It also includes not just the well-known billion dollar entities, but also many small, community oriented and not-for-profit platforms.

Yet, the supposed benefits of a transition from ownership economies to access, collaboration and sharing haven't convinced everyone (Eckhardt and

EIST224BIB0075Bardhi, 2015; Orsi and Doskow, 2009). The strongest criticism centres on whether collaboration and sharing isn't just "capitalism on steroids" (Morovoz, 2013; para.10) extending its

reach to previously informal parts of the economy, while diversifying economic risk to further destructured and precarious labour (Kalamar, 2013; Walker, 2015).

Its market advantage is also viewed as being anchored in a subversion of regulatory and fiscal systems (CNMC, 2016). Furthermore, platforms' radical anti-

establishment ideology has also been questioned, along with any supposed change from individualistic consumption to sustainable practices (Schor, 2014; Hamari

EIST224BIB0260et al., 2015). There is also some doubt about whether it really strengthens social bonds (Bardhi and Eckhardt,

EIST224BIB00252012; Parigi and State, 2014) and

reduces inequalities and discrimination (Edelman and Luca, 2014;

Schor et al., 2016).

Why such conflicting perspectives? Part of the problem seems to reside in the fact that there is no consensus on what sharing and collaborative economies are (Botsman, 2013; Schor, 2014). As Botsman (2015) has pointed out "many terms are being used to describe a broad swath of startups and models that in some way use digital technologies to directly match service and goods providers with customers" (para.1). Attempts to define and understand sharing and collaboration as forms of consumption and social practice can be seen through a number of prisms that taken individually don't appear to provide wholly satisfactory systems with which to grasp the complexity of activity and focus of platforms who share commonalities but that also differ greatly.

In the conceptual overview we examine some of these systems, which include: sectoral classifications, based on offering/transaction type; technological understandings that examine the role of computer architecture and user interfaces that allow peers to engage in stable and safe environments and even build virtual reputations; discourse, representations, and values as a means to define and understand notions of sharing and collaboration, which as we have mentioned are hotly contested; and other approaches, which might be loosely defined as materialist, that seek to cut across preceding approaches to look at what kind of doing or performing occurs during sharing and collaborative practices in their socio-cultural and historic contexts.

\footnotetext{
1 “A private individual who provides, produces or trades goods or services not related to their habitual business, trade or profession" (OCU 2016, p.7).
} 
While, each of these approaches provides valuable insights and understandings, our approach sets out from the materialist viewpoint that technology and socio-cultural meanings are intertwined and inseparable (Sábada and Gordo, 2008). In line with previous research (Finkel et al., 2013;

Cassidy et al., in prep), we present an ethnographic

analysis specific to the case of fifty-five Collaborative Consumption (CC) platforms as the technological and material conditions of possibility for peer-to-peer social interactions in one ambit of the sharing economy. Commissioned by four national consumer organisations the research employs a netnographic research methodology that studies platform architecture, user-interface, design and informational content to examine how technological affordances (Norman, 1988) of digital collaborative consumption platforms structure social production in online interactions. By proposing a typology of three types of collaborative consumption platform that cuts across sectoral, technological and discursive understandings we consider what type of 'doing' these platforms encourage, facilitate or direct and so propose an alternative method of understanding and researching collaborative consumption.

\section{Conceptual overview}

As we outlined above, attempts to define, conceptualise and understand the sharing economy can be broadly considered in terms of four principal areas: sectoral or classificatory definitions, technological understandings, discourse, representations and values and to a limited degree materialist understandings, which take a more holistic and socio-cultural view. These categories are somewhat arbitrary and by no means independent. They also exclude some perspectives; in particular how users appropriate and use technology, as this research focuses on platforms and not users. However, it provides a convenient way to organise the conceptual overview.

\subsection{Technological understandings (infrastructure and functionalities)}

In considering technological understandings of platforms it is possible to consider both how users appropriate technology and how technology is developed, constructed and implemented. Here we forego the user perspective to look at how platforms have structurally reconfigured traditional economic supply chains and market dynamics by putting the technological capabilities in place to create the conditions of possibility for the sharing economy. Through mobile and real-time digital devices and distributed peer-to-peer networks 'prosumers' can take advantage of 'idle resources' to become providers of goods/services not "related to habitual employment or professions" (OCU, 2016; p. 7). In market terms, the technological facilitation of prosumer offerings is complemented by consumer motivations for participating in sharing, which seem to mostly relate to economics (savings) and utilitarianism (convenience) and to a significantly lesser degree environmental ideology and social (networking) capital (OCU, 2016; Hamari et al., 2015). In this respect, two-sided markets, economic platforms that connect two distinct user groups (Hagiu and Wright, 2015),

have been made economically viable through technology. Under this model, the organisation creates value by facilitating the process of offering and finding goods and services or matching provider and consumer.

However, beyond this basic technological functionalism, the relational (social) aspects of exchanges are in some cases critical to how users (prosumer, consumer) are empowered to engage in sharing/collaborative P2P activities. The stability of these networks is, therefore, paramount to the success of the model, and is dependent on how 'strangers' interact, not just technologically but also in offline and, quite often, intimate contexts (room rental, carsahring etc.). To garner such stability platforms enable interactions that reduce the risk of engagement (be it monetized or non-monetized) to levels that the average user feels are safe (Schor, 2014; Pagiri

EIST224BIB0260and Cook, 2015). Using digital technology, platforms have created various systems that facilitate how users present themselves to their peers and how the 'crowd' in turn validates community members. To create trust between users, platforms use ID verification systems, images, personal data, user ratings and reviews, to create dynamic reputational value and trustworthiness (Finley, 2013; Keetels,

EIST224BIB00952013; Parigi and State, 2014),

which subsequently acts as social capital in future exchanges (Pick, 2012). Overall, the technological viewpoint provides us with

two important pieces of the jigsaw: a basic technological structure that organises or facilitates exchanges that can be viewed as somewhat passive and other functionalities that exercise a more active role in the social dynamics of interactions, by facilitating, mediating and, to a degree, controlling exchanges.

\subsection{Classificatory and sectoral definitions}

Within the scope of sharing and collaborative economies, terms such as gig economy, collaborative consumption, peer economy, crowdsourced economy, and on-demand economy, amongst others, are regularly used as interchangeable and synonymous, despite important differences. Added to this complexity is the fact that it also operates in tourism and accommodation, transport, finance, education, heath, and pubic and local administration (Torregrossa, 2013). However, if we examine classificatory understandings in terms of 'offerings' (products, services, etc.), there are two systems that seem to have been most widely utilised. 
Firstly, Botsman and Rogers (2010) identified three sectors: 1) product service systems (carpooling, goods rental, such as RelayRides, Zipcar, bicycle sharing); 2) redistribution (second-hand markets, donations, bartering, classified ads sites such as Craigslist, swapping sites, etc.); and 3) collaborative lifestyles (time banks/skill sharing, micro tasks, garden sharing, repair cafés, including Airbnb, local exchange systems such as Sel du Lac, etc.). Secondly, Schor (2014), developed a classification which included: 1) recirculation of goods (second-hand goods, through sites such as Craigslist or eBay); 2) increased utilization of durable assets (from spare rooms to lawnmowers, incorporating global platforms like Airbnb, but also local non-monetized initiatives such as tool libraries); 3) exchange of services (origins in time-banking, also includes monetized platforms like TaskRabbit); 4) sharing of productive assets (e.g. assets or space, origins in cooperatives, but now also includes with hackerspaces, co-working spaces, and educational platforms like Skillshare.com). The two systems seem broadly comparable, the most notable difference being the inclusion of 'sharing of productive assets or space', which she links to historic cooperatives and hackerspaces, marks a notable difference.

Such classification of activity or offerings into sectors is useful in terms of understanding what is exchanged or transacted on platforms, but in most respects they are either just a transfer of schemata from traditional markets (e.g. rental to access or second-hand to redistribution). Additionally, the distinction between classifications is not entirely clear, for example, in Botsman and Rogers (2010) system 'bartering' is included in 'collaborative lifestyle' yet could also be part of redistribution markets. Schor (2014) includes accommodation services like Airbnb in

utilization of durable assets while Botsman and Rogers (2010)

include it in collaborative lifestyle. However, these semantic distinctions are neither here nor there, the problem lies in that these systems tell us relatively little about the modes of interaction between users and technology, platform's mission or purpose (profit vs. not-for-profit; sustainability, etc.) or much about the socio-cultural and historic contexts of collaborative and sharing economies, which extend back long before the digital (Lamberton, 2016).

\subsection{Discursive understandings and representations of the sharing and collaborative economy}

While the classificatory definitions and technological functionalism give us a general sense of what it is that platforms offer and how they manage to do it, they fail to place collaborative consumption within a socio-cultural context. This is to say that it is also necessary to consider that technology is a social process, intertwined and inseparable from social values (Winner, 2010; Sábada

EIST224BIB0290and Gordo, 2008), meaning that we should look at the social dynamic at the heart of technologies (Hine, 2000). In the introduction we highlighted some of

the macro contextual circumstances of the emergence of the sharing economy, such as economic recession, awareness of environmental sustainability as a social problem and technological development. It is also necessary to look at the term 'sharing', which has been differentially interpreted and applied by platforms, sharing organisations, social scientists, government and opinion leaders, such that it has been justifiably termed a "floating signifier" (Nadeem, 2015 p.13) and as "political and

value-laden" (Lampinen, 2015 p. 2). Within the

debates around what the sharing economy is or isn't, there are a number of perspectives that are worth considering and which are important to the both the research methodology and the interpretation of the results.

Botsman (2013) argues that there is a common core to all the different terms and meanings. She sustains and supports the notion of terms sharing and collaboration as concepts that have a capacity to make significant changes to how we produce and consume. However, as Schor (2014) says, the for-profit platforms haven't been coy about co-opting the term sharing, nor the big world-changing ideas that have struck such a chord with consumers. In this respect, a number of authors claim that the corporate interests of for-profit platforms make the use of the term unsustainable. Belk (2014) calls this "psuedo-sharing" and "a wolf-in-sheep's-clothing phenomenon whereby commodity exchange and potential exploitation of consumer cocreators present themselves in the guise of sharing" (p.1). Similarly, Schor (2015) states that these platforms are more about "earning money (for providers) and managing labour and other costs cheaply (for the platforms) than the feel-good values of sociability, carbon footprint reduction, and efficiency many platforms emphasized when they started out.” (p.14). Agyeman et al. (2013) argue that the "communal, collective production that characterizes the collective commons" (p.5) is missing from current definitions, a point which we return to later as it relates to historic connections with cyber-subculture and digital-commons. On a more academic note, Arnould and Rose (2015)

examine anthropological understandings of gifting and sharing (Mauss, etc.) in order to make sense of the use of the term by authors such as Belk (2010) and Owyang et al.

(2013) to describe systems of resource circulation. They conclude that "attempts to isolate sharing as a discrete form of circulation of consumers goods fails on ontological and epistemological grounds" (Arnould and Rose, 2015;

p.16). Based on an anti-utilitarian conception of the gift they argue that the 'social utilitarian' construct of sharing currently employed is too close to state and market modes, and that grouping together of decontextualised examples of sharing only presents a pretext of similarity.

So, although authors such as Botsman (2015) have proposed evermore sophisticated guides to define 'sharing' businesses, when she claims that "the sharing economy is uniquely placed to reflect our desire as human beings to connect directly and to feel a part of community larger than our individual selves, which serves a purpose far higher than simply the trading of stuff, space and talents" (para.11), it can only be considered as a meaning construction that serves a particular purpose, rather than 
a social reality. From the perspective of this research, three things are important: firstly, social representations related to the sharing or collaborative economies must be considered as political and value laden; and secondly, there should be some differentiation between for-profit and not-for-profit platforms; and thirdly, we must consider how social values influence not only the technological development of platforms, but also how such constructions can mediate users' interactions both with the platform and between peers.

\subsection{Materialist perspectives}

Building on the historic development of capitalism as a creative destructive system Kostakis and Bauwens (2014) developed a four-scenario approach to contemplate value creation, redistribution and economic development in three stages of capitalism, the final stage being a hypothetical mature peer production. Based on two axes or polarities (capital (global) - commons (local); centralised - distributed control of infrastructure) they developed four scenarios or technology regimes, including: netarchical capitalism (centralised control, corporate accumulation of capital, which restricts economic activity and is becoming obsolete); distributed capitalism (decentralised control to individuals, individual accumulation of capital); resilient communities (focus on the common good and adapting to economic, environmental and social crisis at local level); global commons (builds on resilient communities to recognise that local level activity or commons should integrate to global networks). The model helps to solve some of the issues related discussed in the previous section by distinguishing between " $\mathrm{P} 2 \mathrm{P} /$ Commons/sharing practices under the dominance of financialized cognitive capitalism, and a more genuine civil/ethical model centred on the Commons" (Kostakis and Bauwens, 2014

EIST224BIB0155p.72), however, it is theoretical and difficult to practically relate to platform activity.

Taking a goal-based approach, Lamberton (2016) looks at a very broad range of collaborative systems as studied throughout a long history of social scientific research in multiple disciplines. Most notably he proposes that while it might be possible to distinguish between individual, communal or corporate goals, this doesn't mean that there is no cross over between systems or that they don't share characteristics. For example, he argues that "relational sharing might be seen as diametrically opposed to commercial sharing, but both share some characteristics of resource-smoothing" (p.58) and that "task-oriented collaboration may not have relationship development as a focal goal, but may yield relationship gain" (p.58).

Finally, Richardson (2015) considers both the recent history of the sharing economy in cyber sub-cultures and the concept of 'diverse economies' as a context for understanding collaborative economies that would appear to complement the two preceding perspectives. He draws on Amin and Thrift (2004)

work and takes a view of economies as complex and heterogeneous spaces that are interwoven with culture and not separate from it. Through this approach he considers the sharing economy as a collective coming together of practice, discourse and exchange, by examining 'access', 'community' and 'collaboration' as a series of performances "rather than a coherent set of economic practices" (Richardson, 2015;

EIST224BIB0250p.127). By incorporating both history and complexity into his conceptualisation of what the sharing or collaborative economy does, he allows for diversity and paradox and so moves beyond sectoral, technological or rhetorical understandings to ask us to consider what kind of 'doing' or practice platforms or other sharing economy activities facilitate. However, like Lamberton (2016) his approach focuses more on how people or communities engage with sharing and collaboration, while our focus is on technology as a structural and institutional context for social interaction.

Taking these viewpoints together we can arrive at a number of conclusions that shape our approach to the study of the technological features of platforms and the modes of sociability they encourage or discourage. Firstly, the sharing economy and collaborative consumption are rooted in a specific socio-historic context. Secondly, they can be seen as providing the structural (technological) conditions of possibility to fulfil (or create) needs in a cultural context, be they economic, social or environmental (Cassidy et al., in prep).

Thirdly, online communities (users and platforms) are, in a broad sense, associations of people with shared values, meanings and practices (O'Donohoe, 2010). Fourthly, the practices of such communities are diverse, often complementing and contradicting each other at the same time. Finally, online social interactions are mediated, framed or entangled within technological and socio-cultural contexts (Sábada and Gordo, 2008). Therefore, by studying the structure and content of platforms our intention is to examine technological development as a social process, and to develop significant theoretical value, which might help to better understand the impact of collaborative consumption platforms on social production.

\section{Methodology}

\subsection{Netnographic research and observation in digital spaces}

Applying an ethnographic methodology to online spaces represents an important step towards understanding the new realities that are produced through digital technologies. However, with the need to adapt and update ethnographic methods to the digital environment, there are specific characteristics of online social interactions that need to be taken into account (Xun and Reynolds,

2010). Firstly, the term 'virtual', as Kozinets (2010) pointed out, would seem to denote a separate realm

of existence or reality, meaning that it is unsustainable to demarcate between the on line and off line, or to consider that virtual ethnography studies a separate virtual space. This is as true with collaborative consumption platforms as other digital 


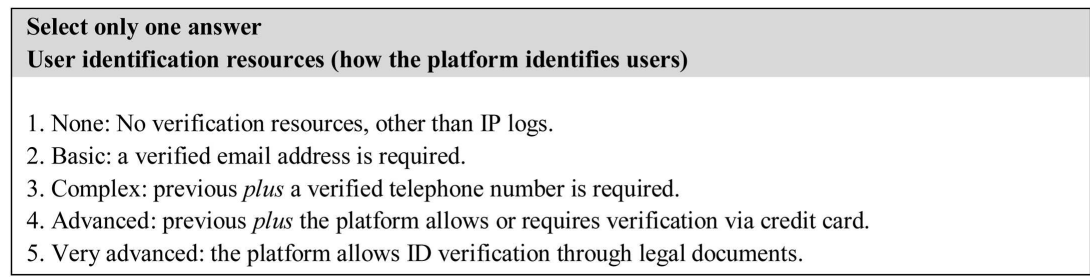

Fig. 1. Example of an observational item (identity and profile building) in the Functionality and Usability dimension.

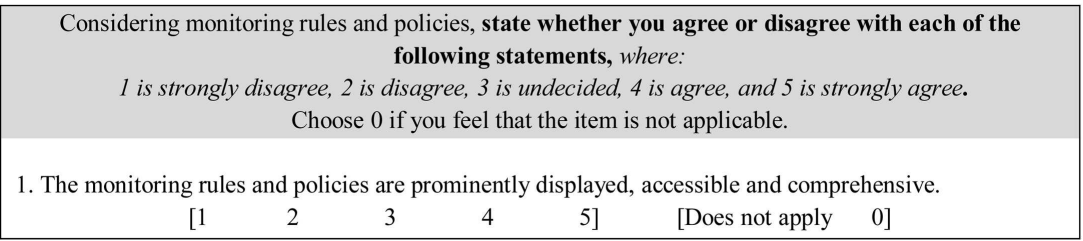

Fig. 2. Example of an evaluation item in the Codes of Conduct dimension.

spaces, which we can think of as hybrid realities between offline and online spaces, in which people engage in collective action and produce symbolic meanings and realities (Pink, 2009; Postill and

Pink, 2012). Secondly, as Hine (2009) proposes that

ethnographic studies of technological practices can focus on "technology development" and/or "technology appropriation", which considers how users adopt, use and interact with technologies. While both perspectives are mutually constitutive this research focuses exclusively on "technological development" and social dynamics, a more structural perspective, per se.

As such, in undertaking such a study we are interested in how technologies as a coalescence of the material (system architecture, user interfaces), discourse and representation (informational content) influence social interactions and hence social production (types of doing). Therefore, the objective behind the methodological design was to enable a systematic study of platform technology and content, as a type of institution, rather than any individual behaviour. To do this we draw on the observational protocols that have been commonly used in ethnography (Creswell, 2007), and more specifically on the "

systematic observation protocols' used in behavioural sciences (Bakeman and Gottman,

EIST224BIB00201997) and 'structured observation' techniques in market research (Grove and Fisk, 1992). However, the study of online environments requires an "adaptive ethnography" and the development of specific methodological approaches, where it is more important to grasp the meanings of the social interactions that are being studied than to follow strict methodological rules or procedures (Hine, 2000, 2008).

Based on the literature review, our own research (Gordo and de

Rivera, 2015), and exploratory observation of platforms, we developed a 'netnographic observational protocol' that systematises data collection by quantifying objective and subjective aspects of platform features and content. The netnographic protocol, therefore, allowed us to transform qualitative observations into quantitative data that could be statistically analysed. In other words, by studying the embedded design and the types of technologically mediated 'doing' that occur on a collaborative consumption platform, we can come to comprehend what platforms themselves understand about collaboration, sharing and consumption, or what authors such as Gehl (2014) refer to as a type of reverse

engineering.

\subsection{Protocol structure and rationale}

Fig. 1 outlines the overall structure and rationale of the four dimensions and sub-items that the protocol measures, which include: 1) functionality and usability of the technology; 2) trust and virtual reputation systems; 3) rules and monitoring technologies or administrative practices related to codes and conduct; and 4) informational content related to community footprint that connects the technological system to a wider socio-cultural context and discourse. Like any such model, the four dimensions are not mutually exclusive, but interrelated, and, in some instances, interdependent. Prior to the fieldwork, the project coordinators from each of the four consumer associations provided feedback on the structure and content of the protocol, which lead to some minor changes.

Before describing the logic of each dimension of the protocol in detail it is worth noting that the protocol includes two measurement items, one objective (observational) and the other subjective (evaluation). Observational items are based on the systematic recording of a website's features, i.e. those features that can be objectively said to exist or not. Observing a range of features the evaluator attributes a score (following a 5-point scale) on the basis of how well developed each feature is from very basic to very advanced (see Fig. 2). Evaluation items are based on a completely subjective evaluation of how the 
platform performs on certain dimensions, and as such takes the perspective of a user. Using a 5-point Likert (agreement) scale, the observer agrees or disagrees with a statement that describes a feature or capacity of the website (see Fig. 3).

\subsection{Dimension I: functionality and usability}

As we outlined in Section 2 the basic technological functionality of platforms is to enable exchange by facilitating 'connections' around an offering (product/service). In order to do so, a platform must, at the very least, permit users to create some form of identity, to post offerings and to communicate with respect to such offerings. At the most basic level of identity and profile building a user may only need to give a name or username and location, but at a more complex level, platforms permit sophisticated identity building giving options to include photos, biographies, videos or status updates. In this sense, we find a dual social function in dimension I, related to 'connectivity' or community building and 'user empowerment'. Apart from identity and profile building, this dimension also observes three other features. Firstly, the type of user status system in place, which evaluates to what degree, if any, a platform allows users to identify other users that offer higher social value. Secondly, the dimension considers functional interactive design, which measures the sophistication of the communicative features for interaction between users. For example, some platforms may have no in-platform feature for communicating, while others have internal messaging, friending etc. Finally, connected services/interconnectivity measures the capacity of the platform to connect users to other platforms or social networks. This dimension also contains seven evaluation items.

\subsection{Dimension II: trust and virtual reputation}

Trust and virtual reputation has become a key socio-technological feature of platforms as stranger sharing necessitates the development of trust to bring stability to the marketplace (Keetels, 2013; Finley,

EIST224BIB01502013; Parigi and State, 2014), as

in any social relations (Lewis and Weigert, 1985). In this respect, it should be noted that the more sophisticated levels of the functionality and usability dimension could be said to crossover into the trust and virtual reputation dimension, and how the design of platforms can enable or promote the accumulation of social capital (Williams, 2006; Pick,

2012). However, our objective is not to measure trust or social capital accumulation, but to measure the technological functionalities that platforms use to generate trust between users. We identified five trust and reputational aspects for inclusion in the protocol. From the literature and Delphi research we conducted with sharing and collaborative economy experts (Cassidy et al., in

EIST224BIB0065prep) we identified cognitive trust (1), emotional trust (2), rating systems (4) and virtual reputation (5). To this we added user identification resources (3), having observed the relevance of ID verification systems on platforms during the exploratory analysis.

Briefly, cognitive trust is knowledge driven and relates to "an individual's ability to process information based on rapid, constitutive cues or first impressions" (Li et al., 2012;

EIST224BIB0175p.90). It is however, subjective and contextual and the "need to trust presumes a state of incomplete knowledge" (Johnson and Grayson, 2005;

EIST224BIB0140p.501). In terms of user interfaces on platforms, this item evaluates the complexity of user profile information and other data that may help users establish cognitive trust. On the other hand, emotional trust relates to less rational evaluations, based more on positive (or negative) affect for the object of trust (Lewis and Weigert, 1985), which in the case of platforms relates to the presence of images, videos, etc. Rating systems relates to the sophistication of the system in place to rate users according to their past performance and involvement with the platform, in what is also termed 'crowd-sourced' verification. Virtual reputation systems represent a more advanced form of rating systems whereby users can develop online virtual reputations or 'second currencies'. This dimension also contains four evaluation items.

\subsection{Dimension III: codes of conduct}

Closely related to trust and virtual reputation, this dimension occupies a different position within the technological and functional architecture of platforms. It includes functionalities that permit platform administrators to monitor, moderate and take action should user behaviour be considered to be against the ethics of the platform or even to be unsafe, as in the case of fraud or impersonation (Cassidy et al., in

EIST224BIB0065prep). As opposed to trust and virtual reputation, which are tools that users employ to build online identity, codes of conduct can be seem as a type of policing function that the platform use to bring stability and security to the network, even if the information/reporting is crowd sourced through 'self-monitoring'. As a factor in online social interactions it is notable that the literature related to this aspect of platform activity is scarce.

We developed three observation items for this dimension. Firstly, the codes of conduct item evaluates the existence of explicit rules or codes for user behaviour and what users should expect from peers. Secondly, block and report assesses the existence of systems that users can employ to report or block other users for misbehaviour, abuse or inappropriate content. At the most advanced level a user can decide who can view their profile without having to justify the decision. Finally, abuse, fraud and impersonation looks at how actively a platform gets involved in issues related to misbehaviour and conduct, 


\begin{tabular}{|c|c|c|c|c|c|c|}
\hline 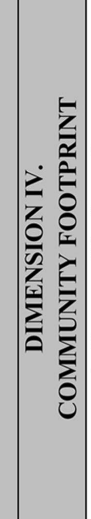 & 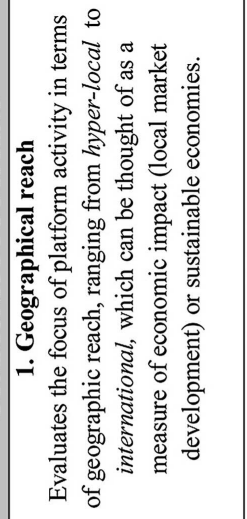 & 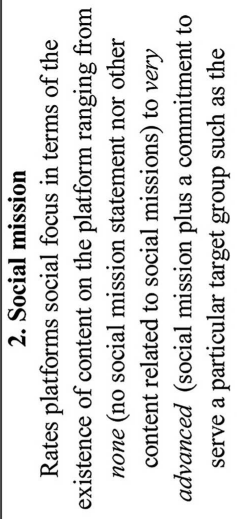 & 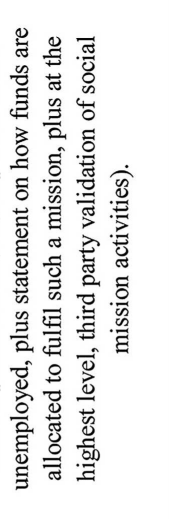 & 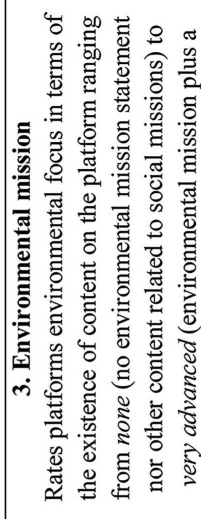 & 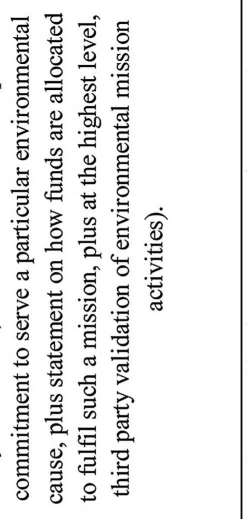 & 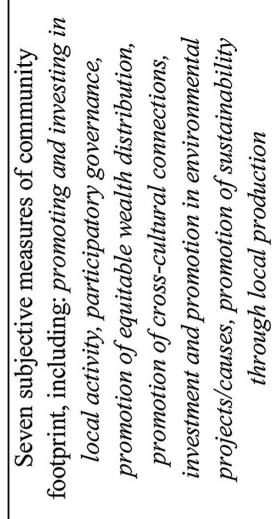 \\
\hline 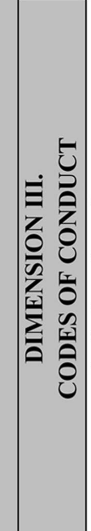 & 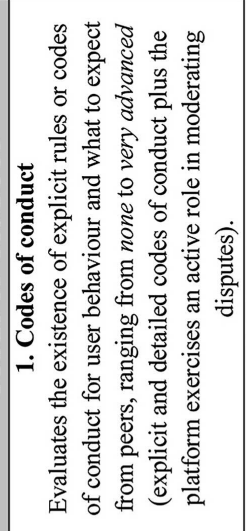 & 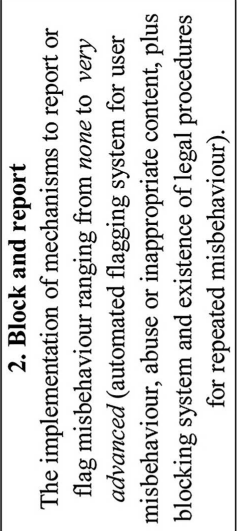 & 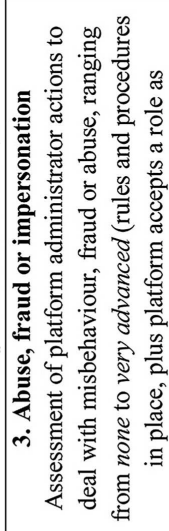 & 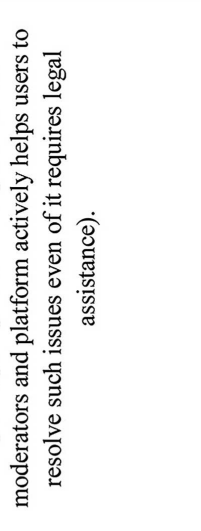 & & 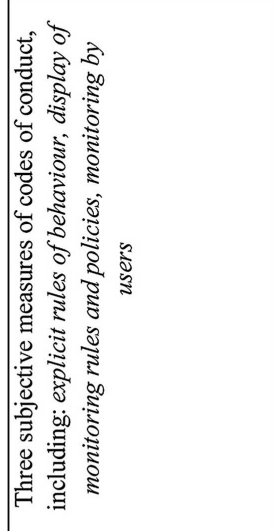 \\
\hline 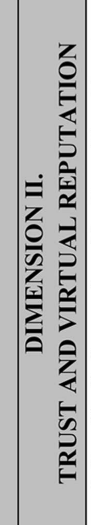 & 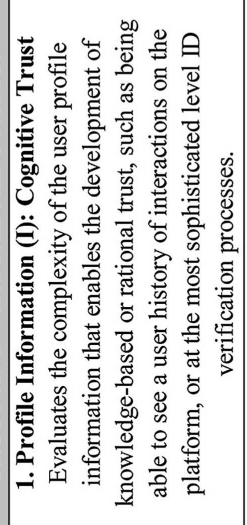 & 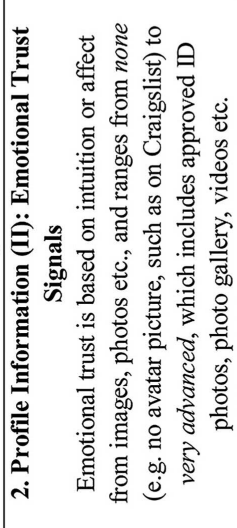 & 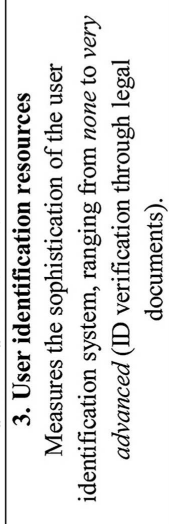 & 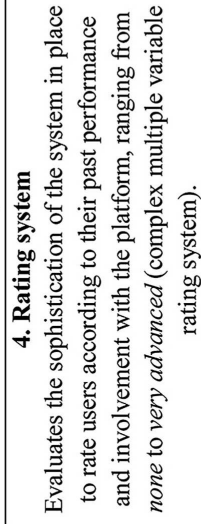 & 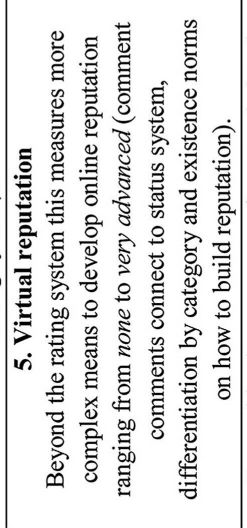 & 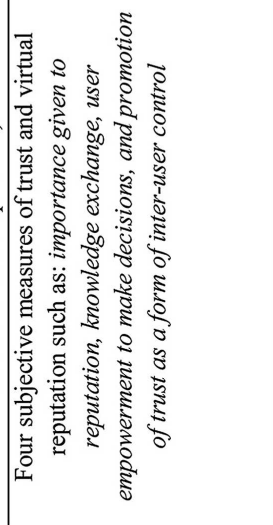 \\
\hline 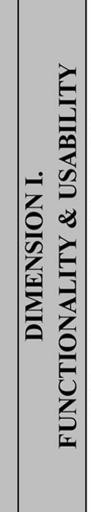 & 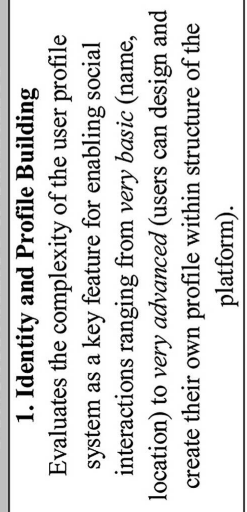 & 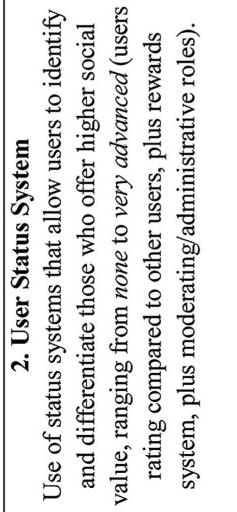 & 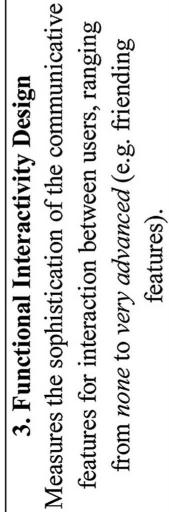 & 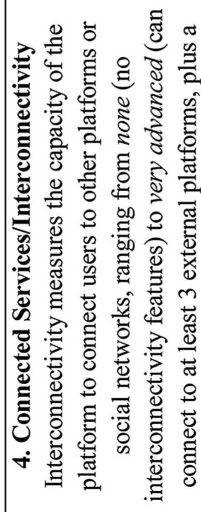 & & 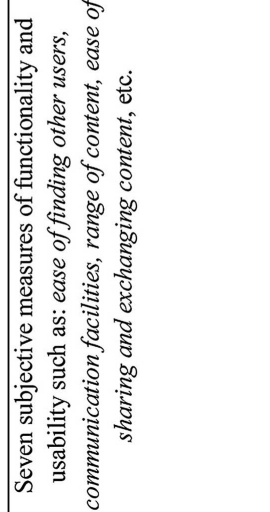 \\
\hline
\end{tabular}


Table 1

Characteristics of the sample.

\begin{tabular}{|c|c|c|c|c|c|}
\hline Sector & $\mathrm{n}$ & $\%$ & Country & $n$ & $\%$ \\
\hline Access instead of property & 20 & 36.4 & Belgium & 15 & 27.3 \\
\hline Redistribution markets & 10 & 18.2 & Italy & 13 & 23.6 \\
\hline \multirow{2}{*}{ Collaborative lifestyle } & 25 & 45.5 & Portugal & 4 & 7.3 \\
\hline & & & Spain & 15 & 27.3 \\
\hline Total & 55 & 100.0 & International & 8 & 14.5 \\
\hline Legal status & $n$ & $\%$ & Total & 55 & 100.0 \\
\hline For-profit & 36 & 65.5 & & & \\
\hline Not-for-profit & 19 & 34.5 & & & \\
\hline Total & 55 & 100.0 & & & \\
\hline
\end{tabular}

ranging from no involvement, to only having published norms, to active moderation and assistance in resolution of issues. This dimension also contains three evaluation items.

\subsection{Dimension IV: community footprint}

As we outlined earlier, the rhetoric of many collaborative consumption platforms purports economic, social and environmental benefits that are often contained within platforms' information content or publicity, which might be said to be an explicit type of discourse related to the socio-cultural relevance of the platforms. In this dimension we examine how the technological functionality of the previous three dimensions is complemented by content related to economic, social and environmental purposes or platform missions. In this respect the three previous dimensions can be seen as focusing on systems that build 'scale' and 'stability' of the network and the 'social capital' of users. Community footprint, on the other hand, considers a connection to broader socio-cultural discourses and the focus of platforms on addressing issues related to economic and environmental sustainability and social issues such as inequality or discrimination.

The dimension contains three observation items. Firstly, the focus of platform activity in terms of geographic reach, ranging from hyper-local to international, which can be thought of as a measure of economic impact (local market development) or sustainable economies, in a similar way that Kostakis and Bauwens

EIST224BIB0155(2014) looked at a polarity between capital (global) and Commons (local). Secondly, social mission rates the platform in terms of content that promotes and makes explicit how and what platforms do to fulfil their social mission, should they have one at all. The final item considers the existence of an environmental mission plus how and what platforms do to fulfil such a mission. Both of these items can be related to Lamberton (2016) goal based classifications in that they identify, to a certain degree, corporate or community focused activity. This dimension also contains seven evaluation items.

\subsection{Sampling and fieldwork}

As a basis for the sampling, and subsequent analysis, we opted to limit the sampling frame based on a number of variables. Firstly, we decided to only look at collaborative consumption platforms, defined as "consumption exchanges between private individuals (or an organized group of individuals) as opposed to the Sharing Economy, a broader socio-economic system around the social paradigms of sharing, collaborating and cooperating" (OCU, 2016; p.7). While this distinction between collaboration and sharing is somewhat imprecise, as there is clearly overlap, it meant that we could subsequently apply a classificatory system to the sample. To do so, we took the general framework of Botsman and Rogers (2010), however, we adapted the category 'product service systems' to 'access instead of property', the only consequence being that platforms such as Airbnb were re-categorised from 'collaborative lifestyle' to the 'access' category. Thirdly, we sought to include forprofit and not-for-profit platforms and finally, the sampling frame was restricted to each of the four participating countries (Spain, Portugal, Belgium and Italy). The four consumer organisations provided a final list of fifty-five platforms that were analysed using the observational protocol. See Table 1 for the statistical characteristics of the sample and Appendix A for a full list of the platforms.

The fieldwork was carried out between May and August 2015. To avoid bias, the netnographic protocol requires at least two researchers (observers) to evaluate each platform, in order to triangulate the observations, or scoring. Authors AJG and JdR carried out the observational research, which didn't necessitate any collaboration from the platforms as the researchers signed up to each platform (if necessary) and interacted with all its technological features, content, messages and procedures as if they were a user. Each platform was evaluated independently by each author and on two occasions to reduce the possibility of systematic and observer bias. In terms of language, AJG and JdR, native Spanish speakers, had the language capabilities to carry out the fieldwork in Spanish, Italian, and Portuguese and to evaluate the French speaking Belgian platforms, however, the Flemish language sites presented some difficulties. In these cases, as with any doubts in the other languages, the authors relied on the assistance (reviewing, checking, interpreting and translating) of the project coordinators from the various consumer associations. Prior to the analysis of the results of the consumer associations reviewed the fieldwork to check for any inconsistencies or errors. 
Table 2

Factor loadings and communalities based on principal components analysis with Varimax rotation for 4 conglomerated items from the protocol.

\begin{tabular}{lll}
\hline Variables & Factor 1 & Factor 2 \\
\hline Trust \& Reputation & 0.88 & - \\
Functionality \& Usability & 0.86 & - \\
Codes of Conduct & 0.73 & - \\
Community Footprint & - & 0.91 \\
\hline
\end{tabular}

Rotation converged in 3 iterations.

Kaiser-Meyer-Olkin Test $=0.617$.

Bartlett's Test $=(\chi 2(6)=68.568 \mathrm{p}<0.001)$.

Table 3

Results of the cluster analysis on the two main factors.

\begin{tabular}{llll}
\hline & Cluster 1 & Cluster 2 & Cluster 3 \\
\hline Factor 1 Score & 0.748 & -1.076 & -0.157 \\
Factor 2 Score & -0.425 & -0.523 & 1.494 \\
\hline
\end{tabular}

\section{Analysis}

Based on previous research (a Delphi study with collaborative consumption and sharing economy experts), which ranked the importance of platform indicators, and on the basis of the literature, each item was accorded a weight depending on the importance of the item, within each category. As objective measures, the observational items were given significantly higher weightings than the evaluation (subjective) items: $80 \%$ in the case of functionality and usability and trust and virtual reputation, $70 \%$ in the case of codes of conduct and 55\% in the final dimensions community footprint. It should be recognized that although the weightings are informed by the Delphi study their calculation is not objective and it is possible that the subjectivities of the authors has led to some bias. In this respect, it is entirely possible that alterations to the weightings would materially influence the results. However, we believe that on the balance of judgment, and the available literature, that the weights are a fair representation of the importance of each item. Multivariate analysis techniques (principal components, factor analysis and non-hierarchical cluster analysis) were used to develop the platform typologies.

\section{Results}

\subsection{Multivariate data analysis}

The first stage of the analysis was to apply the weights to the fifteen observation (objective) items and twenty-one evaluation (subjective) items and to calculate a combined mean score for each of the four dimensions for each platform. Following this process a factor analysis was conducted on the four conglomerated items (functionality and usability, trust and virtual reputation, codes of conduct and community footprint). Firstly, the factorability of the four items was examined and we found that all the variables correlated to at least 0.3 to one other variable, suggesting reasonable factorability. Secondly, the Kaiser-Meyer-Olkin measure of sampling adequacy was 0.617 , above the commonly recommended value of 0.6 , and Bartlett's test of sphericity was significant $\left(\chi^{2}(6)=68.568, p<0.001\right)$. The principal components analysis explained $79.9 \%$ of the variance, giving a two factor output using the orthogonal Varimax rotation method, which looks for greatest degree of simplicity in the matrix by giving greatest importance to the variance of the factorial coefficients to identify latent dimensions that are not inter-correlated.

The data in Table 2 groups together the first three dimensions: functionality and usability, trust and reputation and codes of conduct into the first factor. This means that high levels of positive correlation were found between the scores obtained in these dimensions. The second factor only contained the fourth dimension, community footprint, showing that it was not consistently correlated to any of the other variables. Additionally, some of the categories in the first factor had negative correlations with the community footprint category (second factor).

Following the factor analysis we proceeded to conduct K-means non-hierarchical cluster analysis, an algorithm that groups cases based on the similarity of observations, in this case the two resultant variables from the factor analysis (Table 2). The K-means non-hierarchical method was used as it minimizes intra-group variance while maximising inter-group variance and allows for greater complexity and a more cohesive typology (Martínez-Ramos, 1984). This method also requires the researcher to

define the number of groups in the cluster analysis, which was based on an evaluation the results from the factor analysis in conjunction with theoretical concepts (see Table 3).

\subsection{Typologies of collaborative consumption platforms}

Based on the two groupings derived from the factor analysis and the results of the cluster analysis we identified three groups of platforms that appear to have distinct features in relation to each other. Firstly, a group we define as 'network 
Table 4

Distribution of platforms typologies according to legal status and sector.

\begin{tabular}{|c|c|c|c|c|c|c|c|}
\hline & \multicolumn{2}{|c|}{ Total } & \multicolumn{2}{|c|}{ Legal status $^{\mathrm{a}}$} & \multicolumn{3}{|l|}{ Sector } \\
\hline & $\mathrm{n}$ & $\%$ & $\begin{array}{l}\text { For- profit } \\
\%\end{array}$ & $\begin{array}{l}\text { Not-for-profit } \\
\%\end{array}$ & $\begin{array}{l}\text { Access instead of } \\
\text { property } \\
\%\end{array}$ & $\begin{array}{l}\text { Redistribu-tion } \\
\text { markets }^{c} \\
\%\end{array}$ & $\begin{array}{l}\text { Collabor-ative } \\
\text { lifestyles }{ }^{\mathrm{d}} \\
\%\end{array}$ \\
\hline Network oriented platforms & 26 & 47.3 & 88,5 & 11.5 & 34.6 & 0.0 & 65.4 \\
\hline Transaction oriented platforms & 16 & 29.1 & 75.0 & 25.0 & 37.5 & 43.8 & 18.8 \\
\hline Community oriented platforms & 13 & 23,6 & 7.7 & 92.3 & 38.5 & 23.1 & 38.5 \\
\hline Total & 55 & 100.0 & 65.5 & 34.5 & 34.5 & 18.2 & 47.3 \\
\hline
\end{tabular}

a Pearson's Chi-squared $(25.913, \mathrm{p}<0.001)$.

b Pearson's Chi-squared $(p>0.1)$.

c Pearson's Chi-squared $(13.018, \mathrm{p}<0.005)$.

d Pearson's Chi-squared $(9.024, \mathrm{p}<0.5)$.

Table 5

Mean scores for each of the three typologies in the four dimensions of the protocol.

\begin{tabular}{llllrr}
\hline & Functionality \& Usability & Trust \& Reputation & Codes Of Conduct & Community Footprint & Total \\
\hline All platforms & 2.66 & 3.00 & 2.56 & 2.43 & 2.66 \\
Network oriented platforms & $\mathbf{3 . 2 7}$ & $\mathbf{3 . 6 9}$ & $\mathbf{2 . 7 8}$ & 2.08 & $\mathbf{2 . 9 5}$ \\
Transaction oriented platforms & 2.04 & 2.17 & 1.95 & 2.10 & 2.07 \\
Community oriented platforms & 2.21 & 2.63 & 2.86 & $\mathbf{3 . 5 6}$ & 2.80 \\
\hline
\end{tabular}

Bold = Highest scoring paltform in each dimension and in the total column across all dimesnions.

oriented', which accounts for $47.3 \%$ of platforms, the largest group, and is dominated by platforms from the 'access instead of property' and 'collaborative lifestyle' sectors and contains all of the international platforms. The second group we have denominated the 'transaction oriented' group, which makes up $29.1 \%$ of the total, and contains, in roughly equal part, all three sectors. Finally, the 'community oriented' group makes up $23.6 \%$ of the total and also has a roughly equal distribution of all three sectors (see Table 4). Analysis using Pearson's Chi-squared found that legal status (for-profit vs. not-for-profit) was strongly correlated to the typology $(p<0.001)$ and that the sectoral classification were significant correlated overall $(15.617$, $p<0.05)$. However, when each of the three sectoral classifications were isolated into dummy variables, the product service systems category (access instead of property) was not statistically correlated to the typology, the other two were, though the effect size in collaborative lifestyle was weaker (Table 5).

\subsubsection{Group 1: networking-oriented platforms}

The Network Oriented group had the highest average scores overall, as well as the highest average scores in two of the four dimensions (functionality and usability and trust and reputation), but the lowest score on community footprint. Network oriented platforms place great emphasis on the sophistication of the system architecture and user interface in order to enable highly dynamic, efficient and reliable P2P collaborative interactions. These platforms build on the principles of establishing high levels of interconnectivity and seek stability through the promotion of the social capital of users, which they achieve through elaborate technological functionalities that allow users to build trust and virtual reputation. However, their 'superior' technical features do not generally correspond to a focus on 'collaborative or communitarian culture' through the promotion of social equality or environmental sustainability within the informational content of the platforms' websites. Their focus is on the development of an extensive and stable network, within which users can develop complex online identities and build a virtual reputation and social capital. In this sense, it is evident that these platforms are more focused on individuals as components in a network, rather than community in the sense of social collaboration. However, it should be noted that three of the twenty-three platforms (11.5\%) in this group are non-profits, which, although small, shows that a not-for-profit is not always commensurate with community building. In this respect, it is interesting to note that these platforms are well established with a professionalised management structure. The top ranking platforms in this group are the international, well-known platforms that pioneered the commercial development of collaborative consumption in the digital marketplace, i.e. Airbnb, Blablacar, TimeRepublik, Eatwith. Table 6 provides details of overall scores and how each platform compared within the group and to the total platforms' score.

\subsubsection{Group 2: transaction-oriented platforms}

Overall the transaction-oriented platforms had the lowest scores across all four dimensions. This group is denominated as transaction-focused because, in general, they only put system architecture in place to enable exchanges between users, without those users developing any special identity, self-branding or social capital. Their focus is on systems that facilitate quick and pragmatic exchange through accessibility and dynamism, by facilitating quick and pragmatic interactions. Many of these platforms offer simple services, such as second hand goods, that do not require users to build trust or to develop complex online identities, as is the case in other collaborative or sharing experiences (such as homeswapping, timebanks, 
Table 6

Group 1: Network oriented platforms.

\begin{tabular}{|c|c|c|c|c|c|c|c|c|c|}
\hline \multirow[b]{2}{*}{ Rank } & \multirow[b]{2}{*}{ Platform } & \multirow[b]{2}{*}{ Cnty } & \multirow[b]{2}{*}{$\begin{array}{l}\text { Legal } \\
\text { status }\end{array}$} & \multirow[b]{2}{*}{ Sector } & \multicolumn{5}{|c|}{$\begin{array}{l}\text { Differences between individual platform scores and mean } \\
\text { score of all platforms }\end{array}$} \\
\hline & & & & & $\begin{array}{l}\text { Funct. \& } \\
\text { Usability }\end{array}$ & $\begin{array}{l}\text { Trust \& } \\
\text { Reputation }\end{array}$ & $\begin{array}{l}\text { Codes of } \\
\text { Conduct }\end{array}$ & $\begin{array}{l}\text { Comm. } \\
\text { Footprint }\end{array}$ & Total \\
\hline & & \multicolumn{3}{|c|}{ Mean score of all platforms } & 2.66 & 3.00 & 2.56 & 2.43 & 2.66 \\
\hline 1 & Airbnb & Int. & Profit & Access & 1.34 & 1.35 & 1.64 & -0.03 & 1.12 \\
\hline 2 & Derev & Ita & Profit & Collaborative & 1.32 & 1.10 & 1.14 & 0.32 & 0.93 \\
\hline 3 & Time republik & Int & Profit & Collaborative & 2.17 & 1.05 & -0.36 & 0.02 & 0.73 \\
\hline 4 & Bewelcome & Bel & Not-profit & Access & 1.02 & 0.25 & 1.74 & -0.38 & 0.71 \\
\hline 5 & Blablacar & Int & Profit & Access & 0.74 & 1.00 & 0.64 & -0.03 & 0.61 \\
\hline 6 & Gnammo & Ita & Profit & Collaborative & 1.57 & 1.00 & 0.34 & -0.38 & 0.60 \\
\hline 7 & Woningoppas & Bel & Not-profit & Access & 0.27 & 1.10 & 1.34 & -0.68 & 0.54 \\
\hline 8 & Homelink & Int & Not-profit & Access & 0.97 & 1.00 & 0.74 & -0.88 & 0.52 \\
\hline 9 & Trampolinn & $\mathrm{Sp}$ & Profit & Access & 1.32 & 1.10 & -0.16 & -0.68 & 0.46 \\
\hline 10 & Eatwith & Int & Profit & Collaborative & 0.52 & 1.10 & -0.26 & -0.08 & 0.29 \\
\hline 11 & List minut & Bel & Profit & Collaborative & 0.27 & 1.00 & 0.34 & -0.33 & 0.26 \\
\hline 12 & Mymicroinvest & Bel & Profit & Collaborative & 0.67 & 0.85 & -0.26 & -0.13 & 0.26 \\
\hline 13 & Etece & $\mathrm{Sp}$ & Profit & Collaborative & 0.07 & 1.25 & 0.24 & -0.28 & 0.26 \\
\hline 14 & Home exchang. & Int & Profit & Access & 0.49 & 0.40 & 0.64 & -0.83 & 0.22 \\
\hline 15 & Peoplecooks & Ita & Profit & Collaborative & 0.57 & 0.05 & 0.24 & -0.08 & 0.18 \\
\hline 16 & Prod. dal baso & Ita & Profit & Collaborative & 0.42 & 0.45 & -0.06 & -0.18 & 0.13 \\
\hline 17 & Verkami & $\mathrm{Sp}$ & Profit & Collaborative & 0.42 & 0.60 & -0.46 & -0.08 & 0.10 \\
\hline 18 & Ulule & Int & Profit & Collaborative & 0.49 & 0.60 & -0.46 & -0.28 & 0.07 \\
\hline 19 & Crowdin & Bel & Profit & Collaborative & 1.02 & -0.25 & 0.14 & -0.68 & 0.04 \\
\hline 20 & Ppl & Por & Profit & Collaborative & 0.27 & 0.45 & -0.46 & -0.08 & 0.03 \\
\hline 21 & Bonappetour & Ita & Profit & Collaborative & 0.09 & 0.40 & 0.04 & -0.58 & 0.01 \\
\hline 22 & Housetrip & Por & Profit & Access & 0.24 & 0.35 & 0.34 & -1.13 & 0.00 \\
\hline 23 & Gudog & $\mathrm{Sp}$ & Profit & Collaborative & -0.11 & 0.65 & -0.46 & -0.18 & -0.05 \\
\hline 24 & Social car & Sp & Profit & Access & -0.24 & -0.20 & 0.24 & -0.28 & -0.11 \\
\hline 25 & Trip4real & Sp & Profit & Collaborative & 0.24 & 0.55 & -0.66 & -0.63 & -0.15 \\
\hline 26 & Eslife & Sp & Profit & Collaborative & -0.31 & 0.70 & -0.46 & -0.68 & -0.24 \\
\hline $\begin{array}{l}\text { Total network oriented } \\
\text { platforms }\end{array}$ & & & & & 0.61 & 0.69 & 0.22 & -0.35 & 0.29 \\
\hline
\end{tabular}

carsharing, etc.). In terms of the emphasis placed on social and environment issues (community footprint), these platforms score second lowest overall, but effectively on par with the network-oriented group (2.08 vs. 2.10). In this respect, the platforms are similar, but differentiated in terms of the type of interactions they facilitate or encourage, i.e. based on social capital or not. More notable than in the network group, $25 \%$ of transaction oriented platforms are also not-for-profits.

The platforms that make up this group include both simple underdeveloped platforms (such as Nolotiro) and high-quality commercial platforms (such as HomeAway). Nolotiro is a not-for-profit dedicated to the gifting economy with high scores in community footprint, however its system is so simple that it cannot be considered for Group 2. On the other hand, HomeAway is a high quality platform for house renting, but it is still focused on a centralizedcentralised model of consumption, that does not facilitate the complex P2P interactions that are common in the network-oriented group. In brief, transaction dynamism has greater relevance than the connection between users. Table 7 provides details of overall scores and how each platform compared within the group and to the total score of all platforms (Table 8).

\subsubsection{Community-oriented platforms}

The community-oriented platforms in general obtain high overall scores ( $2.80 \mathrm{vs.} \mathrm{an} \mathrm{average} \mathrm{of} 2.66)$, but still slightly less than the network-oriented platforms (2.95). While this groups scores quite well on functionality and usability, trust and virtual reputation, they have the highest score, by far, in the community footprint dimension and also the highest score in and codes of conduct. In this respect, these platforms' websites place considerable informational emphasis on social and environmental issues, as well as tending to be locally focused. While they score poorly compared to network-oriented platforms on the hard technological dimensions (functionality and usability and trust and virtual reputation), the superior (marginally) score on codes of conduct (2.86 vs. 2.78) is important because when combined with their score on community footprint it provides a profile of platforms that have a strong community and local focus that works towards 'collaborative' communities rather than networks of individuals. These platforms are also frequently focused on non-monetized or alternative currency type exchanges/collaboration and often have not-for-profit legal status and are well established in their communities. In brief, community-oriented platforms tend to focus on the development of connections and interactions within communities, generating services that help social or local initiatives to grow by creating a community of collaboration and sharing rather than pragmatic individualistic exchanges. For example, projects such as WWOFF, La Colmena que dice que Sí or Huertos Compartidos, are focused on organic farming or the growing of food produce for personal consumption, while CiroSel (part of the Système d'Echanges Local in Belgium) is focused on bartering and exchange and closely linked to local communities. 
Table 7

Group 2: Transaction oriented platforms.

\begin{tabular}{|c|c|c|c|c|c|c|c|c|c|}
\hline \multirow[b]{2}{*}{ Rank } & \multirow[b]{2}{*}{ Platform } & \multirow[b]{2}{*}{ Cnty } & \multirow[b]{2}{*}{$\begin{array}{l}\text { Legal } \\
\text { status }\end{array}$} & \multirow[b]{2}{*}{ Sector } & \multicolumn{5}{|c|}{$\begin{array}{l}\text { Differences between individual platform scores } \\
\text { and mean score of all platforms }\end{array}$} \\
\hline & & & & & $\begin{array}{l}\text { Funct. \& } \\
\text { Usability }\end{array}$ & $\begin{array}{l}\text { Trust \& } \\
\text { Reputation }\end{array}$ & $\begin{array}{l}\text { Codes of } \\
\text { Conduct }\end{array}$ & $\begin{array}{l}\text { Comm. } \\
\text { Footprint }\end{array}$ & Total \\
\hline & & Mean & score of all & latforms & 2.66 & 3.00 & 2.56 & 2.43 & 2.66 \\
\hline 1 & Iederen Ruilt & Bel & Not-profit & Redistribution & 0.29 & -0.80 & -0.46 & 0.07 & -0.20 \\
\hline 2 & Creciclando & Sp & Profit & Redistribution & -0.21 & -0.50 & -0.66 & 0.52 & -0.22 \\
\hline 3 & Amovens & $\mathrm{Sp}$ & Profit & Collaborative & 0.02 & -0.15 & -0.36 & -0.88 & -0.31 \\
\hline 4 & Homeaway & Int & Profit & Access & 0.04 & 0.05 & -0.46 & -1.23 & -0.36 \\
\hline 5 & Locloc & Ita & Profit & Access & -0.59 & -0.35 & -0.26 & -0.33 & -0.38 \\
\hline 6 & Manzanas Usa. & $\mathrm{Sp}$ & Profit & Redistribution & -0.89 & -0.50 & 0.74 & -1.03 & -0.42 \\
\hline 7 & Crowdfunding Ita. & Ita & Profit & Collaborative & -0.54 & -0.20 & -0.56 & -0.63 & -0.51 \\
\hline 8 & Boleia & Por & Profit & Access & -0.08 & -0.80 & -1.16 & -0.08 & -0.52 \\
\hline 9 & Repair Cafe & Bel & Not-profit & Collaborative & -1.21 & -1.20 & -1.16 & 1.02 & -0.57 \\
\hline 10 & Segundamano & Sp & Profit & Redistribution & -0.96 & -1.45 & -0.06 & 0.02 & -0.63 \\
\hline 11 & Nolotiro & Sp & Not-profit & Redistribution & -0.71 & -1.05 & -1.56 & 0.77 & -0.65 \\
\hline 12 & Roadsharing & Ita & Profit & Access & -0.66 & -0.40 & -1.56 & -0.48 & -0.78 \\
\hline 13 & Uberpop Brussels & Bel & Profit & Access & -0.94 & -1.30 & -0.26 & -0.68 & -0.79 \\
\hline 14 & Troka Ok & Ita & Not-profit & Redistribution & -1.14 & -1.45 & -0.76 & -0.53 & -0.98 \\
\hline 15 & Percentil & $\mathrm{Sp}$ & Profit & Redistribution & -1.31 & -1.45 & -0.16 & -1.08 & -1.01 \\
\hline 16 & Piggy Bee & Bel & Profit & Collaborative & -1.11 & -1.65 & -1.06 & -0.73 & -1.12 \\
\hline $\begin{array}{l}\text { Total transaction } \\
\text { oriented platforms }\end{array}$ & & & & & -0.62 & -0.83 & -0.61 & -0.33 & -0.59 \\
\hline
\end{tabular}

Table 8

Group 3: Community oriented platforms.

\begin{tabular}{|c|c|c|c|c|c|c|c|c|c|}
\hline \multirow[b]{2}{*}{ Rank } & \multirow[b]{2}{*}{ Platform } & \multirow[b]{2}{*}{ Cnty } & \multirow[b]{2}{*}{$\begin{array}{l}\text { Legal } \\
\text { status }\end{array}$} & \multirow[b]{2}{*}{ Sector } & \multicolumn{5}{|c|}{$\begin{array}{l}\text { Differences between individual platform scores } \\
\text { and mean score of all platforms }\end{array}$} \\
\hline & & & & & $\begin{array}{l}\text { Funct. \& } \\
\text { Usability }\end{array}$ & $\begin{array}{l}\text { Trust \& } \\
\text { Reputation }\end{array}$ & $\begin{array}{l}\text { Codes of } \\
\text { Conduct }\end{array}$ & $\begin{array}{l}\text { Comm. } \\
\text { Footprint }\end{array}$ & Total \\
\hline & & \multicolumn{3}{|c|}{ Mean score of all platforms } & 2.66 & 3.00 & 2.56 & 2.43 & 2.66 \\
\hline 1 & Cirosel (Sel/Lets) & Bel & Not-profit & Collaborative & 0.17 & 0.50 & 0.94 & 0.87 & 0.60 \\
\hline 2 & Cose (In)Utili & Ita & Not-profit & Redistribution & 0.57 & 0.30 & 0.64 & 0.82 & 0.58 \\
\hline 3 & Baratto Matto & Ita & Not-profit & Access & 0.37 & 0.05 & 0.44 & 0.82 & 0.41 \\
\hline 4 & La Colmen. DQS & Sp & Profit & Collaborative & -0.99 & 0.10 & 0.14 & 1.92 & 0.32 \\
\hline 5 & So Crowd & Bel & Not-profit & Collaborative & -0.11 & 0.25 & -0.06 & 0.92 & 0.26 \\
\hline 6 & Reoose & Ita & Not-profit & Access & -0.19 & -0.50 & 0.34 & 1.22 & 0.19 \\
\hline 7 & Tapazz & Bel & Not-profit & Access & -0.49 & 0.10 & 0.64 & 0.57 & 0.18 \\
\hline 8 & Wwoof & Por & Not-profit & Collaborative & -0.94 & -0.10 & -0.06 & 1.47 & 0.12 \\
\hline 9 & Huertos Compart. & Sp & Not-profit & Collaborative & -1.01 & -0.95 & -0.06 & 2.02 & 0.07 \\
\hline 10 & Zero Relativo & Ita & Not-profit & Redistribution & -0.36 & -0.65 & 0.34 & 0.82 & 0.01 \\
\hline 11 & Instrumnetheek & Bel & Not-profit & Access & -1.19 & -1.15 & 0.54 & 1.27 & -0.19 \\
\hline 12 & Freecycle & Bel & Not-profit & Redistribution & -1.04 & -1.65 & 0.64 & 0.87 & -0.34 \\
\hline 13 & Wijdelen (Peerby) & Bel & Not-profit & Access & -0.56 & -1.05 & -0.56 & 0.82 & -0.37 \\
\hline $\begin{array}{l}\text { Total community } \\
\text { oriented platforms }\end{array}$ & & & & & -0.45 & -0.37 & 0.3 & 1.13 & 0.09 \\
\hline
\end{tabular}

\section{Discussion and conclusions}

Following the multivariate factorial and cluster analysis, and on the basis of the theoretical understandings that we outlined earlier, we identified three distinct types of platform that can be understood as permitting and promoting a particular type of 'doing' when consumers/users engage in collaborative consumption. The results of the research should be interpreted within the contexts of the study's limitations. While the sample is relatively large for this type of study, it is not a non-probabilistic sample, being purposive and convenience based, which may lead to some bias. Furthermore, the constructs developed (protocol dimensions) through the literature review and the exploratory analysis more than likely omit some factors, which we hope further research might correct. Additionally, multivariate cluster analysis techniques involve an assessment of both statistical data and theoretical concepts, which means that the researchers own subjectivities can clearly influence the outcome. However, we hope that the validation procedures we employed would negate as much as possible any bias or error in the data collection or interpretation of the results.

The typologies (see Fig. 4) cut across previous sectoral and discursive understandings of collaborative consumption platforms to provide a new perspective, which organizes the platforms we studied into network, transaction and community 


\begin{tabular}{|c|c|c|c|}
\hline $\begin{array}{l}\text { Platform } \\
\text { type }\end{array}$ & $\begin{array}{c}\text { Platform } \\
\text { orientation }\end{array}$ & $\begin{array}{l}\text { Overall scores on the } \\
\text { netnographic protocol }\end{array}$ & $\begin{array}{c}\text { Sectors/ Representative } \\
\text { platforms }\end{array}$ \\
\hline $\begin{array}{l}\begin{array}{l}\text { Network } \\
\text { oriented }\end{array} \\
47 \%\end{array}$ & $\begin{array}{l}\text { - Produces networks of } \\
\text { interests } \\
\text { - Technologically efficient and } \\
\text { sophisticated } \\
\text { - Build social capital through } \\
\text { trust and virtual reputation } \\
\text { systems } \\
\text { - Focused on networks of } \\
\text { individuals rather than } \\
\text { communities or social bonds }\end{array}$ & $\begin{array}{l}\text { - Highest overall scores. } \\
\text { - Particularly high in both } \\
\text { passive and active } \\
\text { technological functionalities } \\
\text { (functionality/usability, trust } \\
\text { and virtual reputation). } \\
\text { - Low scores in community } \\
\text { footprint }\end{array}$ & $\begin{array}{l}65 \% \text { collaborative lifestyle } \\
35 \% \text { access instead of property } \\
\text { International platforms, e.g.: } \\
\text {-AirBnB } \\
\text {-Blablacar, } \\
\text {-TimeRepublik }\end{array}$ \\
\hline $\begin{array}{l}\begin{array}{l}\text { Transaction } \\
\text { oriented }\end{array} \\
29 \%\end{array}$ & $\begin{array}{l}\text { - Pragmatic, utilitarian and } \\
\text { simple exchange interactions } \\
\text { - Technologically efficient and } \\
\text { transaction focused } \\
\text { - No social capital } \\
\text { development } \\
\text { - }\end{array}$ & $\begin{array}{l}\text { - Low scores across all four } \\
\text { dimensions }\end{array}$ & $\begin{array}{l}44 \% \text { Redistribution market } \\
38 \% \text { Access instead of property } \\
19 \% \text { Collaborative lifestyle } \\
\text { E.g: } \\
\text {-Iederen Ruilt (Belgium) } \\
\text {-Nolotiro (Spain) }\end{array}$ \\
\hline \begin{tabular}{|l|}
$\begin{array}{l}\text { Community } \\
\text { oriented }\end{array}$ \\
$24 \%$
\end{tabular} & $\begin{array}{l}\text { - Non-profit focus/ non- } \\
\text { monetized } \\
\text { - Purpose is to build } \\
\text { communities at local level } \\
\text { - Social and environmental } \\
\text { missions }\end{array}$ & $\begin{array}{l}\text { - Medium-high scores overall } \\
\text { Low scores on functionality } \\
\text { and usability and trust and } \\
\text { virtual reputation } \\
\text { - Mid-high score on codes of } \\
\text { conduct } \\
\text { - Highest scores on Community } \\
\text { Footprint }\end{array}$ & $\begin{array}{l}39 \% \text { Access instead of property } \\
19 \% \text { Collaborative lifestyle } \\
23 \% \text { Redistribution market } \\
\text { E.g.: } \\
\text {-Cose (In)Utili (Italy) } \\
\text {-Wwoof (Portugal) }\end{array}$ \\
\hline
\end{tabular}

Fig. 4. Platform typologies.

oriented groupings. Briefly, the network oriented platforms are the highest scoring group overall. They place great emphasis on technological structure as a means to create efficient, stable networks where users can build social capital. However, these platforms score quite low on the community footprint dimension indicating that they are much more focused on users as individual components of networks than they are on building communities in the sense of collaboration. In this sense, while functionalities such as trust and virtual reputation are oriented toward the development of relationships, it is only in the sense of weak or diluted social connections, similar to 'distributed networks' (Wellman et al., 2003).

Group 2, the transaction oriented platforms, had the lowest overall scores. They focus on facilitating pragmatic exchanges, where the focus is on accessibility, speed and convenience rather than the social capital of users. For this reason the technological focus of these platforms is on basic systems that permit connectivity, and there is little pretext of the social or relational (network or community). This isn't to say that the relational doesn't happen, it clearly could, but that it is not promoted by the platforms' technological design.

The third group, community oriented platforms obtained generally high scores, though on average below the network oriented group. While they scored significantly lower on technological functionality (usability and trust and reputation), they scored highest on codes of conduct and by far the highest on community footprint. These platforms have a local focus, with a concern for social and environmental issues. They also tend to be well established in their communities and to have a not-for-profit legal status (with the exception of La colmena dice que sí). Community footprint refers to the promotion of social equality, environmental and economic sustainability as a measurable dimension of platform activity and identity. As such it is an indication of how some platforms (not just those in the community group) promote certain values and practices by offering consumption alternatives.

These platforms' high score on codes of conduct present an interesting scenario. It may be that implementing codes of conduct requires less investment in technology than trust and virtual reputation, making it a more viable option for non-profit platforms, but likewise it may be a particularity of the approach that community oriented platforms take to collaboration. Ostrom (1990), for example, found that the use of formal rules and

norms was critical to the successful management of common pool resource initiatives. In the context of collaborative consumption this distinction between technologically mediated trust and virtual reputation and codes of conduct presents an interesting finding that merits further research. Taken together with community footprint, these community oriented platforms could be said to be somewhat closer to a traditional notion of sharing in the sense of the Commons (Ostrom, 1990) 
or the more recent historical connections between sharing and collaborative economies and hacker or cyber subcultures (Richardson, 2015; Fernández-García

and Moral-Espín , 2016).

The results appear to indicate that while sectoral classifications provide some indication of how to categorize collaborative consumption platforms, it really tells us little about the type of collaboration they mediate, facilitate or promote. This is particularly so in the access instead of property category where we found no significant statistical relationship with the typology. In the other two sectors (collaborative lifestyle and redistribution markets) the relationship is statistically significant. However, even though no redistribution market platforms appeared in the network oriented group, there is a significant possibility that a platform from any of the three sectors could occupy any one of the three groups in the typology. Similarly, when we look at the relationship between legal status (not-for-profit vs. for-profit) there is strong correlation with the resulting typology: community oriented platforms tend to be not-for-profit and network and transaction platforms for-profit. However, in both of these later categories, not-for-profits are also present, accounting for $25 \%$ of the total in the transaction oriented and $11 \%$ in networked oriented group, which suggests that platforms can be both not-for-profit and network or transaction oriented.

The results find some correspondence to the work of Kostakis and Bauwens

(2014). Their 'distributed capitalism' group would appear to relate to our network oriented group in that there is a strong emphasis on decentralisation and empowerment of users to act as prosumers or micro-entrepreneurs, though this entrepreneurial function is not present in all of the platforms in the group. Similarly, our community oriented group relates to their use of 'resilient communities', which reflects a greater concern for the Commons (social and environmental missions) at local level than platforms oriented toward capital accumulation. Kostakis and Bauwens,

(2014) also proposed a 'global commons' group that would take local issues in resilient communities to global level through network integration. Here the models find little correspondence, although the not-for-profit platforms in the network oriented group (for example Homelink and Wonningopass) could perhaps be considered as comparable to this category.

In relation to the debate on real sharing versus psuedo sharing (Belk, 2014), the view that the use of the term

sharing, as employed within collaborative and sharing economy in general, is not sustainable, in the sense that it is used in sociological and anthropological literature (Arnould and Rose, 2015), would seem to be supported, at least partially, by the grouping of the network and transaction oriented platforms. In particular, the transaction oriented group would appear to have a very tenuous link to any form of sharing, as the platforms were not developed with this in mind, which is not to say that users can't appropriate the technology to such an end.

Finally, we should recognise that the typologies we have developed only reflect the types of 'doing' that platforms encourage or mediate through technological structure (design and user interfaces) at the time of the research. The world and technology is dynamic and responsive to social and economic developments, such that platforms will undoubtedly evolve, adapt and acquire new functionalities over time, leading to new orientations and new forms of social production that may necessitate new typologies and new understandings. However, we believe that the present study is a significant step towards a better understanding of how technological affordances of collaborative consumption platforms mediate and structure social interaction.

\section{Conflicts of interest}

The authors have no conflicts of interest to report.

\section{Funding}

The research presented in this article is part of a wider project on the triple impact of P2P collaborative consumption funded by four European consumer associations: Organización de Consumidores y Usuarios [OCU] (Spain), Test Achats (Belgium), Altroconsumo (Italy), and Deco Proteste (Portugal).

\section{Acknowledgements}

We would like to take the opportunity to thank the representatives of the four consumer organisations that funded the research for their help in coordinating the project and for their invaluable insights and feedback.

\section{Appendix A. List of platforms included in the sample}




\begin{tabular}{|c|c|c|c|}
\hline Platform name & Country & Legal status & Sector \\
\hline Airbnb & International & For-For-Profit & Access instead of property \\
\hline Amovens & Spain & For-For-Profit & Collaborative consumption \\
\hline Baratto Matto & Italy & Not-For-For-Profit & Access instead of property \\
\hline Bewelcome & Belgium & Not-For-For-Profit & Access instead of property \\
\hline Blablacar & International & For-For-Profit & Access instead of property \\
\hline Boleia & Portugal & For-For-Profit & Access instead of property \\
\hline Bonappetour & Italy & For-For-Profit & Collaborative consumption \\
\hline Cirosel (Sel/Lets) & Belgium & Not-For-For-Profit & Collaborative consumption \\
\hline Cose (In)Utili & Italy & Not-For-For-Profit & Redistribution markets \\
\hline Creciclando & Spain & For-For-Profit & Redistribution markets \\
\hline Crowdfunding Italy & Italy & For-For-Profit & Collaborative consumption \\
\hline Crowdin & Belgium & For-For-Profit & Collaborative consumption \\
\hline Derev & Italy & For-For-Profit & Collaborative consumption \\
\hline Eatwith & International & For-For-Profit & Collaborative consumption \\
\hline Eslife & Spain & For-For-Profit & Collaborative consumption \\
\hline Etece & Spain & For-For-Profit & Collaborative consumption \\
\hline Freecycle & Belgium & Not-For-For-Profit & Redistribution markets \\
\hline Gnammo & Italy & For-For-Profit & Collaborative consumption \\
\hline Gudog & Spain & For-For-Profit & Collaborative consumption \\
\hline Home exchange & International & For-For-Profit & Access instead of property \\
\hline Homeaway & International & For-For-Profit & Access instead of property \\
\hline Homelink & International & Not-For-For-Profit & Access instead of property \\
\hline Housetrip & Portugal & For-For-Profit & Access instead of property \\
\hline Huertos Compartidos & Spain & Not-For-For-Profit & Collaborative consumption \\
\hline Iederen Ruilt & Belgium & Not-For-For-Profit & Redistribution markets \\
\hline Instrumnetheek & Belgium & Not-For-For-Profit & Access instead of property \\
\hline La Colmen que dice qué sí & Spain & For-For-Profit & Collaborative consumption \\
\hline List minut & Belgium & For-For-Profit & Collaborative consumption \\
\hline Locloc & Italy & For-For-Profit & Access instead of property \\
\hline Manzanas Usadas & Spain & For-For-Profit & Redistribution markets \\
\hline Mymicroinvest & Belgium & For-For-Profit & Collaborative consumption \\
\hline Nolotiro & Spain & Not-For-For-Profit & Redistribution markets \\
\hline Peoplecooks & Italy & For-For-Profit & Collaborative consumption \\
\hline Percentil & Spain & For-For-Profit & Redistribution markets \\
\hline Piggy Bee & Belgium & For-For-Profit & Collaborative consumption \\
\hline Ppl & Portugal & For-For-Profit & Collaborative consumption \\
\hline Prod. dal baso & Italy & For-For-Profit & Collaborative consumption \\
\hline Reoose & Italy & Not-For-For-Profit & Access instead of property \\
\hline Repair Cafe & Belgium & Not-For-For-Profit & Collaborative consumption \\
\hline Roadsharing & Italy & For-For-Profit & Access instead of property \\
\hline Segundamano & Spain & For-For-Profit & Redistribution markets \\
\hline So Crowd & Belgium & Not-For-For-Profit & Collaborative consumption \\
\hline Social car & Spain & For-For-Profit & Access instead of property \\
\hline Tapazz & Belgium & Not-For-For-Profit & Access instead of property \\
\hline Time republik & International & For-For-Profit & Collaborative consumption \\
\hline Trampolinn & Spain & For-For-Profit & Access instead of property \\
\hline Trip4real & Spain & For-For-Profit & Collaborative consumption \\
\hline Troka Ok & Italy & Not-For-For-Profit & Redistribution markets \\
\hline Uberpop Brussels & Belgium & For-For-Profit & Access instead of property \\
\hline Ulule & International & For-For-Profit & Collaborative consumption \\
\hline Verkami & Spain & For-For-Profit & Collaborative consumption \\
\hline Wijdelen (Peerby) & Belgium & Not-For-For-Profit & Access instead of property \\
\hline Woningoppas & Belgium & Not-For-For-Profit & Access instead of property \\
\hline Wwoof & Portugal & Not-For-For-Profit & Collaborative consumption \\
\hline Zero Relativo & Italy & Not-For-For-Profit & Redistribution markets \\
\hline
\end{tabular}

\section{References}

Agyeman, J., McLaren, D., Schaefer-Borrego, A., 2013. Sharing cities. In: Friends of the Earth Big Ideas., pp. 1-33.

Amin, A., Thrift, N.J., 2004. Cultural Economy Reader, Blackwell Readers in Geography., http://dx.doi.org/10.1002/9780470774274.

Arnould, E.J., Rose, A.S., 2015. Mutuality: critique and substitute for Belk's sharing. Mark Theory, http://dx.doi.org/10.1177/1470593115572669 (1470593115572669).

Bakeman, R., M.Gottman, J., 1997. Observing Interaction, second edition. Event, London, http://dx.doi.org/10.1017/CBO9780511527685.

Bardhi, F., Eckhardt, G.M., 2012. Access-based consumption: the case of car sharing. J. Consum. Res. 39, http://dx.doi.org/10.1086/666376.

Barnes, S.J., Mattsson, J., 2016. Understanding current and future issues in collaborative consumption: a four-stage Delphi study. Technological Forecasting Social Change, http://dx.doi.org/10.1016/j.techfore.2016.01.006 (in press).

Belk, R., 2010. Sharing. J. Consum. Res. 36, 715-734, http://dx.doi.org/10.1086/612649.

Belk, R., 2014. Sharing versus pseudo-sharing in web 2.0. Anthropologist 18, 7-23.

Botsman, R., Rogers, R., 2010. What's mine is yours-how collaborative consumption is changing the way we live. Business 274 ,

http://dx.doi.org/10.1016/S0168-9525(00)00086-X.

Botsman, R., 2013. The Sharing Economy Lacks a Shared Definition. Fast Co.

http://www.fastcoexist.com/3022028/the-sharing-economy-lacks-a-shared-definition\#10. 
Botsman, R., 2015. Defining The Sharing Economy: What Is Collaborative Consumption-And What Isn't? Fast Co.

CNMC, 2016. Estudio Sobre Los Nuevos Modelos De Prestacioín De Servicios Y La Economiía Colaborativa-Resultados Preliminares. Comisión Nacional de los Mercados y la Competencia, Madrid, Spain.

Cassidy, P., Gordo, A., de Rivera, J. An exploratory study on the development of indicators to measure the triple impact (economic, social and environmental) of Collaborative Consumption platforms: a Delphi research technique. in prep.

Creswell, J.W., 2007. Qualitative Inquiry and Research Design: Choosing Among Five Approaches. Sage.

Eckhardt, G.M., Bardhi, F., 2015. The sharing economy isn't about sharing at all. Harvard. Bus. Rev., 1-3.

Edelman, B., Luca, M., 2014. Digital discrimination: the case of Airbnb.com. Harvard Bus. Sch. 21, http://dx.doi.org/10.2139/ssrn.2377353.

Fernández-García, M., Moral-Espín, L., 2016. La ética hacker frente al capitalismo netárquíco: software libre y peer production en las iniciativas de Economía Colaborativa en Andalucía. Teknokultura. Rev. Cult. Digit. y Movimientos Soc. 13.

Finkel, L., Gordo López, A., Guarino, A., 2013. La investigación en las redes sociales: una propuesta metodológica. In: Crisis Y Cambio: Propuestas Desde La Sociología.

Finley, K., 2013. Trust in the Sharing Economy: an Exploratory Study. Centre for Cultural Policy Studies - University, Warwick, pp. 81.

Gehl, R.W., 2014. Reverse Engineering Social Media: Software Culture and Political Economy in New Media Capitalism. Temple University Press.

Gordo, A., de Rivera, J., 2015. The triple impact assessment of P2P collaborative consumption in europe. In: Research Report, with the Collaboration of María Avizanda (Desk Research \& Delphi Study Research Assistant) (October).

Grove, S.J., Fisk, R.P., 1992. Observational data collection methods for services marketing: an overview. J. Acad. Mark. Sci. 20, 217-224, http://dx.doi.org/10.1007/BF02723408.

Hagiu, A., Wright, J., 2015. Multi-sided platforms. Int. J. Ind. Organ. 43, 162-174, http://dx.doi.org/10.1016/j.ijindorg.2015.03.003.

Hamari, J., Sjöklint, M., Ukkonen, A., 2015. The sharing economy: why people participate in collaborative consumption. SSRN Electron. J., 1-19, http://dx.doi.org/10.2139/ssrn.2271971.

Hine, C., 2000. Virtual ethnography. In: The Sage Handbook of Research Methods., http://dx.doi.org/10.4135/9780857020277.

Hine, C., 2008. Virtual ethnography: modes, varieties affordances. In: SAGE Handbok Online Research Methods., http://dx.doi.org/10.4135/9780857020277.

Hine, C., 2009. How can qualitative internet researchers define the boundaries of their projects? In: Internet Inquiry Conversations About Method., pp. 1-20, http://dx.doi.org/10.4135/9781483329086.n1.

Johnson, D., Grayson, K., 2005. Cognitive and affective trust in service relationships. J. Bus. Res. 58, 500-507, http://dx.doi.org/10.1016/S0148-2963(03)00140-1.

Kalamar, A., 2013. Sharewashing is the new greenwashing. OpEd News, Retrieved from: http://www.opednews.com/articles/SharewashingistheNewGrbyAnthonyKalamar130513834.

Keetels, L., 2013. Collaborative Consumption. The Influence of Trust in Sustainable Peer-to-peer Product-service Systems. Masters Thesis. Environmental Policy and Management. Faculty of Geosciences, Utrecht University.

Kostakis, V., Bauwens, M., 2014. Network Society and Future Scenarios for a Collaborative Economy. Palgrave Macmillan, http://dx.doi.org/10.1057/9781137406897.

Kozinets, R.V., 2010. Netnography: Doing Ethnographic Research Online. Sage, http://dx.doi.org/10.2501/S026504871020118X.

Lamberton, C., 2016. Collaborative consumption: a goal-based framework. Curr. Opin. Psychol., http://dx.doi.org/10.1016/j.copsyc.2015.12.004.

Lampinen, A., 2015. Deceptively simple: unpacking the notion of sharing. Soc. Media + Soc. 1, 1-2, http://dx.doi.org/10.1177/2056305115578135.

Li, F., Pieńkowski, D., Van Moorsel, A., Smith, C., 2012. A holistic framework for trust in online transactions. Int. J. Manag. Rev., http://dx.doi.org/10.1111/j.1468-2370.2011.00311.x.

Martínez-Ramos, E., 1984. Aspectos teóricos del Análisis de Cluster y aplicación a la caracterización del electorado potencial de un partido. In: Introducción a Las Técnicas De Análisis Multivariable Aplicadas a Las Ciencias Sociales.

Morozov, E., 2013. The “sharing economy” undermines workers' rights. In: Financial Times. \#axzz4J11500UM.

Nadeem, S., 2015. Introduction. In: Schor, J. (Ed), On the Sharing Economy. Contexts. 14 (1. 13). https://contexts.org/articles/on-the-sharing-economy/.

Nielsen, 2014. Is sharing the new buying? reputation and trust are emerging as new currencies report. In: Global Survey of Share Communities (Retrieved from) http://www.nielsen.com/content/dam/nielsenglobal/apac/docs/reports/2014/Nielsen-Global-Share-Community-Report.pdf.

Norman, D., 1988. The Psychology of Everyday Things. Basic books, http://dx.doi.org/10.2307/1423268.

O'Donohoe, S., 2010. Netnography: doing ethnographic research online-Robert V Kozinets. Int. J. Advert. 29, 328, http://dx.doi.org/10.2501/S026504871020118X.

Ostrom, E., 1990. Governing the Commons: The Evolution of Institutions for Collective Action. Cambridge University Press, Cambridge.

Owyang, J., Tran, C., and Silva, C. The Collaborative Economy: A market definition report. Altimeter Research Theme: Digital Economies. 2013, (Retrieved from)

http://www.collaboriamo.org/media/2014/04/collabecon-draft16-130531132802-phpapp02-2.pdf.

PWC, 2015. The Sharing Economy Consumer Intelligence Series. Price Waterhouse Coopers Report (Retrieved from) http://www.pwc.com/us/en/industry/entertainment-media/publications/consumer-intelligence-series/assets/pwc-cis-sharing-economy.pdf.

Pagiri, P., Cook, K., 2015. Trust and relationships in the sharing economy. In: Schor (Ed.) on the sharing economy. Contexts 14 (1), 12-19.

Parigi, P., State, B., 2014. Disenchanting the world: the impact of technology on relationships. Soc. Informatics 8851, 166-182, http://dx.doi.org/10.1007/978-3-319-13734-6_12.

Pick, F., 2012. Building Trust in Peer-to-Peer Marketplaces: an Empirical Analysis of Trust Systems for the Sharing Economy Bachelor Thesis. Communication Department Zeppelin University.

Pink, S., 2009. Doing Sensory Ethnography. Sage, http://dx.doi.org/10.4135/9781446249383.

Postill, J., Pink, S., 2012. Social media ethnography: the digital researcher in a messy web. Media Int. Aust., 123-134.

Richardson, L., 2015. Performing the sharing economy. Geoforum 67, 121-129, http://dx.doi.org/10.1016/j.geoforum.2015.11.004.

Schor, J.B., Fitzmaurice, C., Carfagna, L.B., Attwood-Charles, W., 2016. Paradoxes of openness and distinction in the sharing economy. Poetics, http://dx.doi.org/10.1016/j.poetic.2015.11.001.

Schor, J., 2014. Debating the sharing economy. Great Transit. Initiat. Essay, 1-19.

Schor, J., 2015. Getting sharing right. In: Schor, J. (Ed.) on the sharing economy. Contexts 14 (1), 12-19.

Torregrossa, M., 2013. The sharing economy. training toolkit based on strength, weaknesses, opportunities and threats (SWOT). In: European Sharing Economy Coalition. Presentation (Retrieved from) http://es.slideshare.net/speed101/the-rise-of-the-sharing-economy.

Walker, E., 2015. Beyond the rhetoric of the sharing economy. In: Schor, J. (Ed.), On the Sharing Economy. Contexts 14 (1), 12-19.

Wellman, B., Quan-Haase, A., Boase, J., Chen, W., Hampton, K., Díaz, I., Miyata, K., 2003. The social affordances of the Internet for networked individualism. J. Comput. Mediated Commun. 8 (3).

Williams, D.C., 2006. On and off the 'Net: scales for social capital in an online era. J. Comput. Commun. 11, 593-628, http://dx.doi.org/10.1111/j.1083-6101.2006.00029.x.

Winner, L., 2010. The Whale and the Reactor: A Search for Limits in an Age of High Technology. University of Chicago Press.

Xun, J., Reynolds, J., 2010. Applying netnography to market research: the case of the online forum. J. Targeting, Meas. Anal. Mark 18, 17-31, http://dx.doi.org/10.1057/jt.2009.29. 